\title{
The relationship between demographic features, anthropometric parameters, sleep hours, and physical activity and ECG parameters in Fasa Persian cohort study
}

\section{Alireza Mirahmadizadeh}

Non Communicable Diseases Research Center, Department of Epidemiology, School of Health, Shiraz University of Medical Sciences, Shiraz, Iran

\section{Mojtaba Farjam}

Non Communicable Diseases Research Center, Department of Epidemiology, School of Health, Shiraz University of Medical Sciences, Shiraz, Iran

\section{Mehdi Sharafi ( $\square$ mehdisharafi_2002@yahoo.com)}

Shiraz University of Medical Sciences, Shiraz, Iran

\section{Hossein Fatemian}

Shiraz University of Medical Sciences, Shiraz, Iran

\section{Maryam Kazemi}

Non Communicable Diseases Research Center, Department of Epidemiology, School of Health, Shiraz University of Medical Sciences, Shiraz, Iran

\section{Kiarash Roustai Geraylow}

Semnan University of Medical Sciences, Semnan, Iran

\section{Azizallah Dehghan}

Non Communicable Diseases Research Center, Department of Epidemiology, School of Health, Shiraz University of Medical Sciences, Shiraz, Iran

\section{Zahra Amiri}

Hormozgan University of Medical Sciences, Hormozgan, Iran.

\section{Sima Afrashteh}

Shiraz University of Medical Sciences, Shiraz, Iran

\section{Research Article}

Keywords: Anthropometric parameters, Sleep hours, ECG parameters, Cohort

Posted Date: February 15th, 2021

DOl: https://doi.org/10.21203/rs.3.rs-183576/v1 
License: (c) (i) This work is licensed under a Creative Commons Attribution 4.0 International License. Read Full License 


\section{Abstract}

Backgrounds: Cardiovascular Diseases (CVDs) are the first leading cause of death worldwide. The present study aimed to investigate the relationship between demographics, anthropometrics, sleep time, and physical activity and ECG parameters in Fasa Persian cohort study.

Methods: In this cross-sectional study, the basic information of 10,000 participants aged 35-70 years in Fasa cohort study was used. The information used in this study included demographic data, main Electrocardiogram (ECG) parameters, anthropometric data, sleep time, and physical activity. Data analysis was performed using t-test, chi-square, and linear regression model.

Results: The findings of this study suggested that increased age was significantly associated with all study parameters. Nevertheless, gender and body mass index showed no significant relationship with SV3 and PR. Wrist circumference $\mathbb{X}$ hip circumference, and waist circumference significantly increased the mean values of the ECG parameters. However, sleep time was not significantly associated with the ECG parameters. In addition, hypertension was a major comorbidity, which was shown to increase the mean values of the ECG parameters.

Conclusion: A number of factors affected the ECG parameters. Thus, in order to interpret ECGs, in addition to age and gender, anthropometric indices, physical activity, and previous history of comorbidities, such as hypertension and ischemic heart disease, should be taken into consideration.

\section{Introduction}

Cardiovascular Diseases (CVDs) are one of the first leading cause of death worldwide (1). In 2016, it was estimated that 17.9 million people died from CVDs, accounting for $31 \%$ of all global deaths (2). In addition to high mortality, CVDs have considerable complications and are a major cause of certain disabilities, especially in old ages (3). Therefore, establishment of screening programs among high-risk populations aimed at reducing the mortality rate is of paramount importance (4). Electrocardiography (ECG) also known as electrocardiogram is an affordable, non-invasive, easy-to-apply, and widely used method to screen heart diseases (5). Experimental evidence has shown that many CVDs can be effectively diagnosed, controlled, and prevented through continuous monitoring and analysis of ECG signals (6). Therefore, monitoring of physiological signals, such as ECG signals, is a comprehensive technique for evaluation, control, and prevention of CVDs (7). However, the role of ECG in CVDs screening is still controversial and under debate in many studies (8).

A number of authors have defined population-based reference values based on specific populations. However, it is obvious that ECG screening is influenced by a variety of factors, including demographics and anthropometrics (9-11). Previous studies have shown that males had prolonged PR interval, wider QRS duration, and shorter QTC interval compared to females. In addition, in both genders, older age was associated with longer PR interval and wider QRS duration, while higher Body Mass Index (BMI) was linked to prolonged PR interval, wider QRS duration, and significantly negative QRS axis ${ }^{0}$ (12). Generally, 
identification and management of patients with coronary artery disease is highly dependent on ST wave changes, T-wave inversion, and Q-wave presentation. Less than $50 \%$ of people with Myocardial Infarction (MI) showed ST-wave changes in their initial ECG (13). T-wave changes were also shown to be associated with myocardial ischemia, and T-wave inversion was an important indicative of this disease (14). Furthermore, ECG abnormalities were associated with an increased risk of adverse cardiac events, including hypertrophic cardiomyopathy (15), fast heartbeat, prolonged PR interval and QT inversion, and abnormal changes in ECG axes (16). Moreover, elevated PR interval increased the risk of atrial fibrillation and $\mathrm{MI}$ in the elderly population (17). Furthermore, the results of the previous studies demonstrated that higher BMI was positively associated with QRS duration, indicating that higher weight increased the odds of ventricular depolarization disturbances (12). Dhingra and colleagues also disclosed that increased QRS duration was positively associated with left ventricular hypertrophy, with a significantly stronger association amongst obese males (18).

ECG screening is commonly used to identify pathological processes, such as lethal arrhythmias associated with short- or long-term QT interval. Although such conditions rarely occur in young and healthy populations, early detection can prevent the catastrophic complications of sudden cardiac death (8). Due to the limited number of related studies conducted on the middle-aged population of Iran, this study aims to evaluate the relationship between demographic and anthropometric variables and ECG parameters in the middle-aged population of Fasa Persian cohort.

\section{Methods}

In this cross-sectional study, basic information of the participants enrolled in Fasa cohort study was used. This cohort consisted of 10,000 people aged 35-70 years, and was conducted in Shashdeh region with 24 villages. The study data, including demographics, socioeconomic status, routine tests, sample preparation in biobanks, physical examinations, anthropometric measurements, physical activity, sleep patterns, nutritional status, and ECG, were stored as online digital information for each individual [19]. The required data included ECG parameters such as QTc bazzet interval (ms), QRS duration (ms), QRS axis $^{0}$, PR interval (ms), RaVL amplitude (mv), and SV3 amplitude (mv), demographics including age, gender, education level, and marital status, anthropometrics like BMI, wrist circumference, hip circumference, and waist circumference, physical activity [Metabolic Equivalent of Task (MET)], and the 24-hour sleep time, which were selected from the basic cohort information. Out of the 10,000 participants of the cohort, only 7,119 had recorded ECGs. All these participants had 12-lead ECGs prior to the interview. They were asked to shave the precordium area for better attachment of the ECG electrodes. All ECG records were stored in a standard format and were converted into quantitative and electronic formats by a specific analog-to-digital converter (Cardiax $\AA)$. Then, they were automatically connected to the basic information of the individuals (19).

The quantitative results were expressed as mean and standard deviation and the qualitative results as frequency and percentage. T-test and chi-square test were used to compare the variables by gender. Additionally, one-dimensional linear regression model was used and the variables with the significance 
level of less than 0.25 were entered into the multivariate model to eliminate the effect of confounders. Due to the presentation of collinearity between the anthropometric variables, physical activity in the multivariate model, other variables were controlled and the variables were separately entered into the model. The significance level was set at 0.05 .

\section{Results}

A total of 7119 participants were recruited into this study, 3092 ones of whom (43.43\%) were male. The mean age of the participants was $48.59 \pm 9.34$ years, and there was no significant age difference between males and females. Comparison of the characteristics of all study participants by gender has been presented in Table 1. The results revealed significant differences between males and females with respect to all variables, except for age and amount of sleep per day $(p<0.001)$.

\section{Correlation between age and ECG parameters}

The results of the linear regression model showed that age was positively associated with ECG parameters, including PR (ms) $(B=0.275, p<0.001), Q R S(m s)(B=0.047, p=0.005), Q T C \quad(B=0.331$, $p<0.001)$, and $\operatorname{RaVL}(\mathrm{mm})(B=0.003, p<0.001)$. As such, increase in age by one year after the age of 35 years increased the average ECG parameters, including PR (0.275), QRS (0.047), QTC (0.331), and RaVL $(0.003 \mathrm{~m} / \mathrm{s})$, but significantly decreased SV3 $(\mathrm{mm})(b=-0.002, p<0.001)$ and QRS axis $(b=-0.454, p<0.001)$ (Tables 2-7).

\section{The relationship between gender and ECG parameters}

The results of multivariate analysis showed that gender was significantly associated with all ECG parameters, except for S in V3. After adjusting for the effects of other variables, the average intervals between PR, QRS, and QRS axis parameters were reduced by $-6.03,-4.070$, and -8.43 units, respectively among females $(p<0.001)$. Females also displayed an increased QTC interval and RaVL amplitude by 16.82 and 0.096 units, respectively compared to males $(p<0.001)$ (Tables $2-7)$.

\section{The relationship between marital status and ECG parameters}

According to the results presented in tables 2-7, marital status showed no significant relationship with any of the ECG parameters ( $p>0.05)$ (Tables 2-7).

\section{The relationship between BMI and ECG parameters}

After controlling the effects of other variables, BMI was significantly associated with R in Avl, S in V3, QRS axis, QTC, and QRS. Accordingly, increase in BMI by one point elevated the average interval of $\mathrm{R}$ in $\operatorname{aVL}(0.016, p<0.05)$, QTC $(0.316,-1.42)$, and QRS $(0.235, p<0.001)$, but decreased the interval of $S$ in V3(-0.003) and QRS axis $(-1.42)(p<0.001)$ (Tables 2-7).

\section{The relationship between education level and ECG parameters}


The effect of education level in the multivariate model showed that this variable was not significantly linked to any of the ECG parameters ( $p>0.05)$ (Tables 2-7).

\section{The relationship between wrist circumference and ECG parameters}

The findings of the present study showed a significant relationship between wrist circumference and PR, QRS, S in V3, QRS axis, QTC, and R in aVL. Based on the results, increase in wrist circumference by one $\mathrm{cm}$ increased the average interval of PR, QRS, QTC, and R in aVL by $1.501,0.855,1.32$, and 0.040 units, respectively $(\mathrm{p}<0.001)$. Increase in wrist circumference by one $\mathrm{cm}$ also resulted in a decrease in the QRS axis and $S$ in $V 3$ by 3.45 and 0.008 units, respectively $(p<0.001)$ (Tables $2-7)$.

\section{The relationship between hip circumference and ECG parameters}

The results indicated that hip circumference significantly associated with $S$ in $V 3, R$ in aVL, QRS, QTC, and PR parameters. After controlling the effects of other variables, increase in hip circumference by one centimeter increased the mean interval of R in aVL, QTC, QRS, and PR parameters by $0.006,0.152,0.151$, and 0.253 , respectively $(p<0.001)$, but decreased the mean interval of $S$ in $V 3$ and QRS axis by -0.001 and -598 , respectively $(p<0.001)$.

\section{The relationship between waist circumference and ECG parameters}

Among Iranian adults, waist circumference was shown to be significantly associated with all ECG parameters. After controlling the effects of other variables, increase in waist circumference by one centimeter increased the mean interval of PR (0.190), QRS (0.101), and R in aVL $(0.006)(p<0.001)$, but decreased the mean interval of QTC $(-0.234)$, QRS axis $(-0.553)$, and $S$ in $V 3(-0.001)(p<0.001)$ (Tables 27).

\section{The relationship between MET and ECG parameters}

In the present study, MET showed a significant relationship with QTC, QRS, and R in aVL. Accordingly, increase in MET by one unit decreased the mean interval of QTC and R in aVL by -0.234 and -0.0005 , respectively $(p<0.05)$, but increased the mean interval of QRS axis by $0.096(p=0.023)$ (Tables 2-7).

\section{The relationship between diabetes and ECG parameters}

Among the participants of this cohort, diabetes was not significantly associated with any of the ECG parameters in the multivariate model $(p>0.05)$ (Tables 2-7).

\section{The relationship between hypertension and ECG parameters}

In this study, after adjusting for the effects of other variables, hypertension showed a significant relationship with PR, QRS, S in V3, QRS axis, QTC, and R in aVL. Accordingly, PR, QRS, QTC, and R in aVL increased by $2.40,0.998,2.423$, and 0.081 units, respectively among hypertensive individuals $(p<0.05)$. 
Besides, the mean intervals of QRS and S in V3 parameters were reduced by 3.48 and -0.030 units, respectively in hypertensive people compared to non-hypertensive ones $(p<0.05)$ (Tables $2-7)$.

\section{The relationship between cardiac ischemic disease and ECG parameters}

The patients with cardiac ischemic disease showed a significant relationship only with $\mathrm{R}$ in $\mathrm{aVL}$, such a way that the mean interval of $\mathrm{R}$ in aVL increased by 0.022 in these patients compared to the healthy individuals after controlling the effects of other variables $(p=0.011)$. This variable showed no significant associations with other ECG parameters ( $p>0.05$ ) (Tables 2-7).

\section{The correlation between the total amount of sleep in 24 hours and ECG parameters}

Among the Iranian adults of this cohort, the total amount of sleep in 24 hours was not significantly associated with any of the ECG parameters in the multivariate model ( $p>0.05)$ (Tables 2-7).

\section{Discussion}

This cross-sectional study was conducted on 7119 individuals aged 35-75 years who participated in the Fasa cohort study. The results indicated that the participants with higher BMI had longer QT interval, wider QRS complex, higher R wave amplitude in aVL, lower QRS axis, and lower S wave amplitude in V3. Moreover, higher anthropometrics, such as wrist, waist, and hip circumference, were associated with longer PR interval, QRS complex, higher R wave amplitude in aVL, and lower QTc interval, QRS axis, and S wave amplitude in V3. Similar results were reported by T. Maruyama et al. (20) who found that lengthening of PR interval and QRS duration and a leftward shift of the QRS axis was associated with $\mathrm{BMI}$ increment.

The $\mathrm{P}$ wave in ECG reflects the atrial contraction, which occurs first in the right and then in the left atrium, creating a positive upward wave in leads I, II, AVL, and AVF. Atrial repolarization creates a small wave that is not detectable on ECG, because it is covered by a QRS wave. The QRS wave represents ventricular contraction, and the ventricular repolarization is highlighted by T wave. Changes in the amplitude or interval of the waves can either occur in a normal range or indicate pathology in the mechanics or electrics of arteries (21).

The results of the present study suggested that increase in age increased the QRS, PR, QT, and R in aVL intervals. Numerous studies on ECG changes at different age groups have also shown that the PR, QRS (8), and QT (22) intervals were shortened by age. Since the risk of $\mathrm{Ml}$, atrial fibrillation, and left ventricular hypertrophy increases with age and prolongation of PR and QRS interval duration may manifest in the presence of these diseases $(12,18)$, the results of the present study were expected and justifiable.

In the current research, QRS, PR, and QRS axis intervals were shorter in females than in males, which was consistent with the results of other studies $(12)(11,23)$. Hence, physicians should pay attention to gender and gender differences in ECG interpretations. 
The results also demonstrated that QRS, QT, and $\mathrm{R}$ in aVL intervals increased with elevated BMI. These results were in agreement with the results of other studies regarding the relationship between obesity and QRS, QT, and PR prolongation $(9,24)$. Prolonged PR can be a sign of myocardial hypertrophy, while it is asymptomatic in many cases and occurs due to anatomical changes of the chest in obese people (24). The findings of the present study also showed that the elevation of other anthropometric indices, such as wrist circumference, waist circumference, and hip circumference, was associated with increased QRS, PR, and $\mathrm{R}$ in V1 in ECG. Waist circumference has been one of the widely used criteria for metabolic syndrome, which is one of the most common determinants of ECG changes along with hypertension among these people. Abdominal obesity raises the diaphragm, resulting in increased sympathetic activity and cardiac output, thereby affecting the ECG parameters (25).

Exercise and physical activity has been known to be a protective factor against CVDs. However, in athletes and individuals who have constant and intense physical activity, it causes structural and electrical changes in the heart including bradycardia sinus, first-degree Atrioventricular (AV) block, and early repolarization, which are displayed in ECG. Other less common changes in athletes' ECGs include prolongation or shortening of QT, pathological Q-wave, changes in the ST segment, and enlargement of the right atrium (26). In the present study, prolongation of QT and R in aVL was associated with increased physical activity. Due to the rural nature of the study population, physical activity of this population was higher than the average physical activity of the urban population.

In general, patients with diabetes are at a higher risk for ischemic heart disease due to macro and microvascular complications, which can be completely asymptomatic in the normal 12-lead ECG due to diabetic neuropathy. However, nonspecific changes are usually observed in the ECGs of these patients. Tachycardia and shortening of QT and QRS intervals are the examples of these changes that are justified by increased sympathetic tone in these patients (27). In the current study, diabetes was not associated with any significant changes in the ECG.

The present study findings demonstrated that hypertension was associated with prolonged QRS, PR, QT, and $\mathrm{R}$ in aVL durations, which was supported by the results of other studies (24). High blood pressure causes left ventricular hypertrophy over time and presents as QT prolongation in the ECG (28).

A cohort study of 3777 elderly Asians showed that the participants with higher BMls had a longer PR interval, wider QRS, more negative QRS axis, and a larger RaVL (29). A cross-sectional study on 11,308 participants also indicated that an increment in BMI and central obesity increased PR interval and $P$ wave duration (30). Braschi et al. (31) found that the QT interval and QTc interval significantly increased in obese compared to normal-weight participants. However, they revealed no association between obesity with QT dispersion and QT apex dispersion. Similarly, Fraley et al. (32) reported prolonged QT interval duration, QTc interval, and leftward shifts of the P wave, QRS, and T wave axes, and various markers of left ventricular hypertrophy among the obese participants. Another study conducted on rats demonstrated that there were no rhythm disturbances early in obesity. The results only revealed an increase in the resting heart rate. The observed ECG abnormalities suggested ventricular changes related to impaired 
myocardial depolarization and repolarization and cardiac morphology changes (33). Central obesity has been shown to significantly increase the risk of coronary heart disease. It has been hypothesized that waist circumference is an indicator of visceral obesity, which results in insulin resistance and its associated cardiovascular risk factors (34).

Another important finding of the current investigation was that the participants with higher physical activity, evaluated by a higher MET score, had a higher QRS axis, shorter QTc interval, and shorter R wave amplitude in aVL. Nevertheless, no significant association was reported between sleep duration and the ECG parameters. It has been expressed that regular physical activity positively affected the vagal activity on the heart (35). Lawan et al. (36) reported a higher prevalence of sinus bradycardia, first-degree AV block, and right and left axis deviation in athletes compared to non-athletes. They also found right bundle branch block, prolonged QT interval, and elevation of the J point only among the athletes. On the contrary, Melanson EL et al. (37) stated that heart rate and Heart Rate Variability (HRV) were highly reproducible regardless of the physical activity level. Their results suggested that although HRV might be greater in physically active participants than in nonactive individuals, no dose-dependent association was found between the physical activity level and HRV.

The present study results showed a longer PR interval, QTc interval, QRS complex, higher R wave amplitude in $\mathrm{VVL}$, lower QRS axis, and S wave amplitude in V3 among the hypertensive participants compared to the non-hypertensive ones. Ch. Sia et al. (38) disclosed that systolic blood pressure of $>140 \mathrm{mmHg}$ or diastolic blood pressure of $>90 \mathrm{mmHg}$ independently increased the prevalence of increased QRS voltage on ECG. The current study findings also indicated higher $\mathrm{R}$ wave amplitude in the patients with ischemic heart disease, while no significant ECG changes were found in those with diabetes. However, Noori et al. (39) found higher QT interval, QTd interval, QTc interval, and QTcd interval in patients with diabetes. Most of the ECG abnormalities in diabetes patients reported by the previous studies were more pronounced in patients with cardiac autonomic neuropathy. In comparison to similar ECG changes in other diseases, ECG changes in diabetes patients were not specific and were mainly caused by an increased tone of the sympathetic nervous system, which was indirectly confirmed by the heart rate variability findings in patients with diabetes (40). In addition, hypertension and diabetes, as risk factors for CVDs, might cause major pathological changes in the ECG parameters by causing myocardial ischemia.

One of the strengths of this study was its large sample size. In addition, the effects of confounding factors, such as age, gender, physical activity, and comorbidities, were considered in the evaluation of changes in the ECG parameters. However, the study limitations included its cross-sectional design and recruitment of the people aged over 35 years. Hence, the results are required to be confirmed in further longitudinal studies with longer follow-up periods on populations with a more extensive age range.

\section{Conclusion}


In conclusion, the study findings revealed a correlation between the ECG parameters and anthropometric indicators, physical activity status, and previous history of such comorbidities as hypertension and ischemic heart disease. Hence, these factors have to be taken into consideration in the interpretation of ECG signals. Moreover, it is necessary to account for the factors associated with ECG parameters according to each population's racial and ethnic characteristics and provide normal and abnormal ECG interpretation implications as guidelines to physicians.

\section{Declarations}

\section{Acknowledgement}

The authors would like to thank Ms. A. Keivanshekouh at the Research Improvement Center of Shiraz University of Medical Sciences for improving the use of English in the manuscript.

\section{References}

1. Global Status Report on non-communicabal diseases 2010.

2. WHO fact sheet. Available from: https://who.int/news-room/fact-sheets/detail/cardiovasculardiseases-cvd.

3. Acharya UR, Fujita H, Lih OS, Adam M, Tan JH, Chua CK. Automated detection of coronary artery disease using different durations of ECG segments with convolutional neural network. KnowledgeBased Systems. 2017;132:62-71.

4. Maron BJ, Friedman RA, Kligfield P, Levine BD, Viskin S, Chaitman BR, et al. Assessment of the 12lead ECG as a screening test for detection of cardiovascular disease in healthy general populations of young people (12-25 years of age) a scientific statement from the American Heart Association and the American College of Cardiology. Circulation. 2014;130(15):1303-34.

5. Levy D, Bailey J, Garrison R, Horton M, Bak S, Lyons D, et al. Electrocardiographic changes with advancing age. A cross-sectional study of the association of age with QRS axis, duration and voltage. Journal of electrocardiology. 1987;20:44-7.

6. Preejith S, Dhinesh R, Joseph J, Sivaprakasam M, editors. Wearable ECG platform for continuous cardiac monitoring. 2016 38th Annual International Conference of the IEEE Engineering in Medicine and Biology Society (EMBC); 2016: IEEE.

7. Serhani MA, T El Kassabi H, Ismail H, Nujum Navaz A. ECG Monitoring Systems: Review, Architecture, Processes, and Key Challenges. Sensors. 2020;20(6):1796.

8. Sia CH, Dalakoti M, Tan BY, Lee EC, Shen X, Wang K, et al. A Population-wide study of electrocardiographic (ECG) norms and the effect of demographic and anthropometric factors on selected ECG characteristics in young, Southeast Asian males-results from the Singapore Armed Forces ECG (SAFE) study. Annals of Noninvasive Electrocardiology. 2019;24(3):e12634. 
9. Frank S, Colliver JA, Frank A. The electrocardiogram in obesity: statistical analysis of 1,029 patients. Journal of the American College of Cardiology. 1986;7(2):295-9.

10. Fraley M, Birchem J, Senkottaiyan N, Alpert M. Obesity and the electrocardiogram. Obesity 2005;6(4):275-81.

11. Macfarlane P, McLaughlin S, Devine B, Yang T. Effects of age, sex, and race on ECG interval measurements. Journal of electrocardiology. 1994;27:14-9.

12. Tan ES, Yap J, Xu CF, Feng L, Nyunt SZ, Santhanakrishnan R, et al. Association of age, sex, body size and ethnicity with electrocardiographic values in community-based older Asian adults. Heart, Lung and Circulation. 2016;25(7):705-11.

13. 1 Mahmoodzadeh S, Moazenzadeh M, Rashidinejad H, Sheikhvatan M. Diagnostic performance of electrocardiography in the assessment of significant coronary artery disease and its anatomical size in comparison with coronary angiography. Journal of research in medical sciences: the official journal of Isfahan University of Medical Sciences. 2011;16(6):750.

14. Amirzadegan A, Hosseini K, Moghaddam ES, Nozari Y, Tajdini M. Upright T Wave in Lead V1 as an Important Predictor of Significant Coronary Artery Disease in Patients with Chest Pain. Zahedan Journal of Research in Medical Sciences. 2017;19(12).

15. Corrado D, Basso C, Schiavon M, Thiene G. Screening for hypertrophic cardiomyopathy in young athletes. New England Journal of Medicine. 1998;339(6):364-9.

16. O'Neill J, Bounford K, Anstey A, D'Silva J, Clark L, Plein S, et al. P wave indices, heart rate variability and anthropometry in a healthy South Asian population. PloS one. 2019;14(8):e0220662.

17. Cheng M, Lu X, Huang J, Zhang S, Gu D. Electrocardiographic PR prolongation and atrial fibrillation risk: a meta-analysis of prospective cohort studies. Journal of cardiovascular electrophysiology. 2015;26(1):36-41.

18. Dhingra R, Nam BH, Benjamin EJ, Wang TJ, Larson MG, D'Agostino RB, et al. Cross-sectional relations of electrocardiographic QRS duration to left ventricular dimensions: the Framingham Heart Study. Journal of the American College of Cardiology. 2005;45(5):685-9.

19. Farjam M, Bahrami H, Bahramali E, Jamshidi J, Askari A, Zakeri $H$, et al. A cohort study protocol to analyze the predisposing factors to common chronic non-communicable diseases in rural areas: Fasa Cohort Study. BMC Public Health. 2016;16(1):1-8.

20. Maruyama, T., et al., Correlations between Anthropometrics and Electrocardiographic Variables in Japanese University Students: Investigation by Annual Health Screening. Cardiology and Angiology: An International Journal, 2017: p. 1-12.

21. Mirvis DM, Goldberger AL. Electrocardiography. Heart disease. 2001;1:82-128.

22. Shinmura K, Ebihara Y, Kawamura M, Tani M, Nakamura Y. Changes in electrocardiographic findings with aging in a longitudinal study of 500 apparently healthy persons aged 60 years and older. Nihon Ronen Igakkai zasshi Japanese journal of geriatrics. 1994;31(5):366-73.

23. Simonson E, BLACKBURN JR H, PUCHNER TC, Eisenberg P, Ribeiro F, Meja M. Sex differences in the electrocardiogram. Circulation. 1960;22(4):598-601. 
24. PIPBERGER HV, GOLDMAN MJ, Littmann D, MURPHY GP, Cosma J, SNYDER JR. Correlations of the orthogonal electrocardiogram and vectorcardiogram with constitutional variables in 518 normal men. Circulation. 1967;35(3):536-51.

25. Yazdanpanah MH, Sayyadipoor S, Hojati SR, Nikmanesh A, Farjam M, Homayounfar R. The Association of Metabolic Syndrome and Its Components with Electrocardiogram Parameters and Abnormalities Among an Iranian Rural Population: The Fasa PERSIAN Cohort Study. Diabetes, Metabolic Syndrome and Obesity: Targets and Therapy. 2020;13:2975.

26. Corrado D, Pelliccia A, Heidbuchel H, Sharma S, Link M, Basso C, et al. Erratum: Recommendations for interpretation of 12-lead electrocardiogram in the athlete (European Heart Journal (2010) 31 (243259)). European heart journal. 2010;31(3):379.

27. Noori NM, Teimouri A, Nakhaee Moghadam M, Kasravi M. Evaluation of Electrocardiographic Parameters in Diabetes Mellitus Type I in Children and Adolescent. International Journal of Pediatrics. 2019;7(9):10057-66.

28. Chapman N, Mayet J, Ozkor M, Foale R, Thom S, Poulter N. Ethnic and gender differences in electrocardiographic QT length and QT dispersion in hypertensive subjects. Journal of human hypertension. 2000;14(6):403-5.

29. Tan, E.S.J., et al., Association of Age, Sex, Body Size and Ethnicity with Electrocardiographic Values in Community-based Older Asian Adults. Heart, Lung and Circulation, 2016. 25(7): p. 705-711.

30. Vaidean, G.D., M. Manczuk, and J.W. Magnani, Atrial electrocardiography in obesity and hypertension: Clinical insights from the Polish-Norwegian Study (PONS). obesity, 2016. 24(12): p. 2608-2614

31. Braschi, A., et al., Novel Electrocardiographic Parameters of Altered Repolarization in Uncomplicated Overweight and Obesity. Obesity, 2011. 19(4): p. 875-881.

32. Fraley, M., et al., obesity and the electrocardiogram. Obesity reviews, 2005. 6(4): p. 275-281.

33. Mutiso, S.K., DK. Rono, and F. Bukachi, Relationship between anthropometric measures and early electrocardiographic changes in obese rats. BMC Research Notes, 2014. 7(1): p. 931.

34. Smith, D.A., et al., Abdominal diameter index: a more powerful anthropometric measure for prevalent coronary heart disease risk in adult males. Diabetes, Obesity and Metabolism, 2005. 7(4): p. 370-380.

35. Melo, R., et al., Effects of age and physical activity on the autonomic control of heart rate in healthy men. Brazilian journal of medical and biological research, 2005. 38(9): p. 1331-1338

36. Lawan, A., M. Ali, and SD. Bauchi, Evaluation of 12-lead electrocardiogram (ECG) in athletes and nonathletes in Zaria, Nigeria. Pakistan journal of Physiology, 2008. 4(1): p. 27-29.

37. Melanson, E.L., Resting heart rate variability in men varying in habitual physical activity. Medicine and science in sports and exercise, 2000. 32(11): p. 1894-1901.

38. Sia, C.-H., et al., A Population-wide study of electrocardiographic (ECG) norms and the effect of demographic and anthropometric factors on selected ECG characteristics in young, Southeast Asian males-results from the Singapore Armed Forces ECG (SAFE) study. Annals of Noninvasive Electrocardiology, 2019. 24(3): p. e12634. 
39. Noori, N.M., et al., Evaluation of Electrocardiographic Parameters in Diabetes Mellitus Type I in Children and Adolescent. International Journal of Pediatrics, 2019. 7(9): p. 10057-10066.

40. Kittnar, O., Electrocardiographic changes in diabetes mellitus. Physiological research, 2015. 64: p. S559.

\section{Tables}

Table 1. The demographic characteristics and the correlated variables by gender 


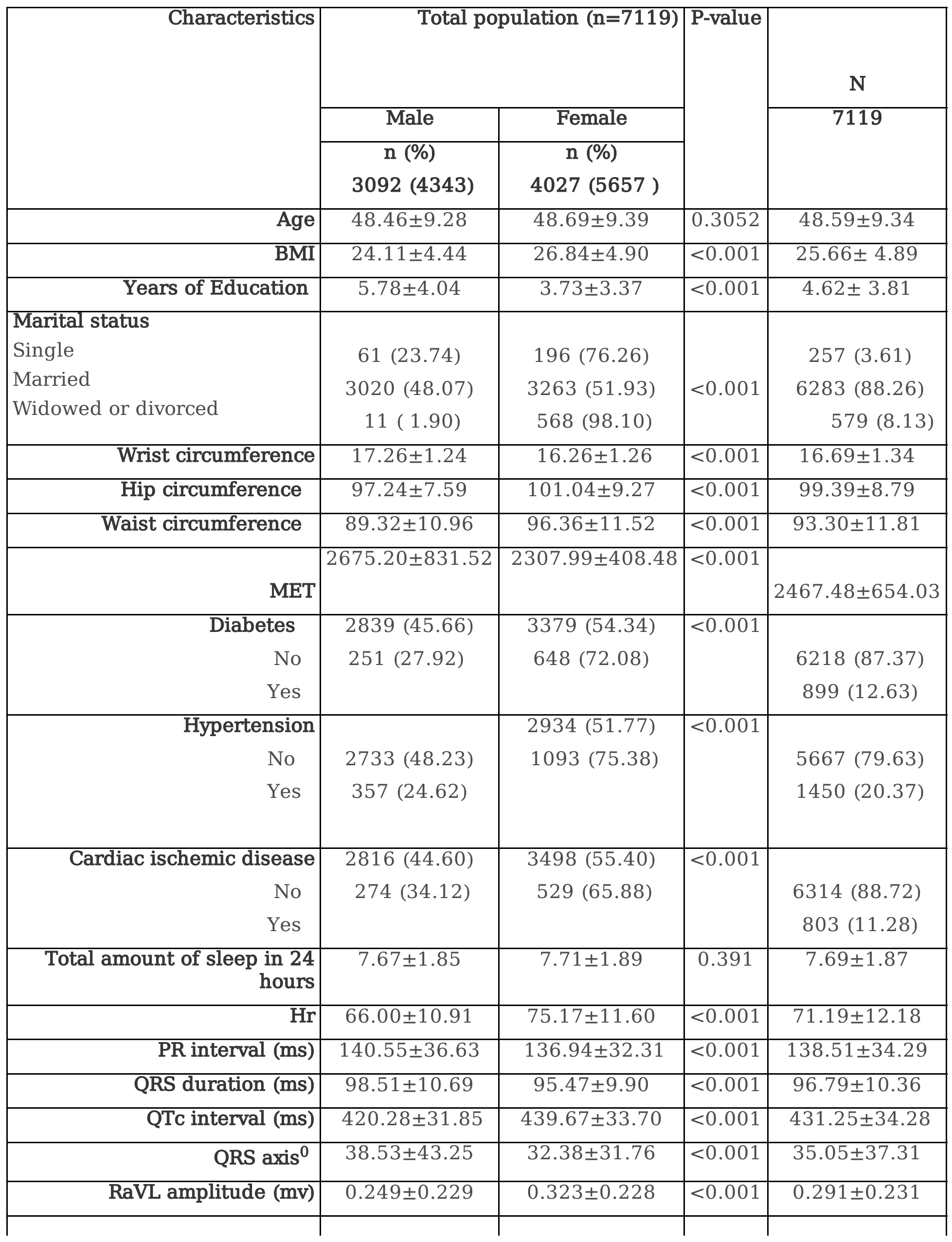


BMI, body mass index; MET, metabolic equivalent of task

\begin{tabular}{|c|c|c|c|c|c|c|}
\hline \multirow[t]{2}{*}{ Variables } & \multicolumn{3}{|l|}{ Crude } & \multicolumn{3}{|c|}{ Adjusted } \\
\hline & $\bar{B}$ & $95 \% \mathrm{~B}$ & P-value & $\bar{B}$ & $95 \% \mathrm{~B}$ & P-value \\
\hline Age & 0.298 & $0.213,0.383$ & $<0.001$ & 0.275 & $0.203,0.347$ & $<0.001$ \\
\hline $\begin{array}{l}\text { Gender } \\
\text { Male } \\
\text { Female }\end{array}$ & $\begin{array}{l}\text { Ref } \\
-3.61\end{array}$ & $-5.21,-2.00$ & $<0.001$ & -6.63 & $-7.85,-5.42$ & $<0.001$ \\
\hline $\begin{array}{l}\text { Marital status } \\
\text { Unmarried } \\
\text { Married } \\
\text { Widowed or divorced }\end{array}$ & $\begin{array}{l}\text { Ref } \\
3.11 \\
3.40\end{array}$ & $\begin{array}{l}-1.159,7.398 \\
-1.63,8.44\end{array}$ & $\begin{array}{c}0.153 \\
0.185\end{array}$ & $\begin{array}{l}-0.200 \\
-0.083\end{array}$ & $\begin{array}{l}-2.98,2.580 \\
-3.40,3.23\end{array}$ & $\begin{array}{l}0.888 \\
0.961\end{array}$ \\
\hline $\mathrm{BMI}$ & 0.261 & $0.098,0.423$ & 0.002 & & & \\
\hline Education level & -0.307 & $-0.515,-0.098$ & 0.004 & 0.016 & $\begin{array}{l}-0.153 \\
0.185\end{array}$ & 0.851 \\
\hline Wrist circumference & 1.75 & $1.169,2.348$ & $<0.001$ & 1.50 & $0.860,2.14$ & $<0.001$ \\
\hline Hip circumference & 0.149 & $0.058,0.239$ & 0.001 & 0.253 & $0.158,0.348$ & $<0.001$ \\
\hline Waist circumference & 0.133 & $0.066,0.201$ & $<0.001$ & 0.190 & $0.143,0.236$ & $<0.001$ \\
\hline MET & 0.047 & $-0.025,0.121$ & 0.202 & 0.018 & $\begin{array}{l}-0.031 \\
0.069\end{array}$ & 0.471 \\
\hline $\begin{array}{l}\text { Diabetes } \\
\text { No } \\
\text { Yes }\end{array}$ & $\begin{array}{l}\text { Ref } \\
2.69\end{array}$ & $0.298,5.09$ & 0.028 & .087 & $-1.50,1.68$ & 0.914 \\
\hline $\begin{array}{l}\text { Hypertension } \\
\text { No } \\
\text { Yes }\end{array}$ & $\begin{array}{l}\text { Ref } \\
3.691\end{array}$ & $1.714,5.668$ & $<0.001$ & 2.40 & $0.963,3.83$ & 0.001 \\
\hline $\begin{array}{l}\text { Cardiac ischemic } \\
\text { disease } \\
\text { No } \\
\text { Yes }\end{array}$ & $\begin{array}{l}\text { Ref } \\
2.08\end{array}$ & $-0.430,4.60$ & 0.104 & 0.687 & $-1.01,2.39$ & 0.429 \\
\hline $\begin{array}{l}\text { Total amount of sleep in } \\
24 \text { hours }\end{array}$ & -0.097 & $-0.521,0.326$ & 0.651 & - & - & - \\
\hline
\end{tabular}

BMI, body mass index; MET, metabolic equivalent of task 


\begin{tabular}{|c|c|c|c|c|c|c|}
\hline \multirow[t]{2}{*}{ Variables } & \multicolumn{3}{|l|}{ Crude } & \multicolumn{3}{|c|}{ Adjusted } \\
\hline & $\bar{B}$ & $95 \%$ B & P-value & B & $95 \%$ B & P-value \\
\hline Age & 0.103 & $0.078,0.129$ & $<0.001$ & 0.047 & $0.014,0.080$ & 0.005 \\
\hline $\begin{array}{l}\text { Gender } \\
\text { Male } \\
\text { Female }\end{array}$ & $\begin{array}{l}\text { Ref } \\
-3.03\end{array}$ & $-3.51,-2.55$ & $<0.001$ & -4.070 & $-4.63,-3.50$ & $<0.001$ \\
\hline $\begin{array}{l}\text { Marital status } \\
\text { Unmarried } \\
\text { Married } \\
\text { Widowed or divorced }\end{array}$ & $\begin{array}{l}\text { Ref } \\
3.395 \\
2.578\end{array}$ & $\begin{array}{c}2.10,4.68 \\
1.058,4.098\end{array}$ & $\begin{array}{l}<0.001 \\
0.001\end{array}$ & $\begin{array}{l}1.18 \\
1.099\end{array}$ & $\begin{array}{l}-0.107 \\
2.468 \\
-0.437 \\
2.635\end{array}$ & $\begin{array}{l}0.072 \\
0.161\end{array}$ \\
\hline$\overline{\mathrm{BMI}}$ & 0.148 & $0.099,0.197$ & $<0.001$ & 0.235 & $\begin{array}{l}0.184 \\
0.286\end{array}$ & $<0.001$ \\
\hline Education level & -0.063 & $\begin{array}{l}-0.126 \\
-.0003\end{array}$ & 0.049 & -0.066 & $\begin{array}{l}-0.145 \\
, 0.011\end{array}$ & 0.095 \\
\hline Wrist circumference & 1.20 & $1.02,1.38$ & $<0.001$ & 0.855 & $\begin{array}{l}0.665 \\
1.046\end{array}$ & $<0.001$ \\
\hline Hip circumference & 0.101 & $0.073,0.128$ & $<0.001$ & 0.151 & $0.123,0.179$ & $<0.001$ \\
\hline Waist circumference & 0.070 & $0.050,0.090$ & $<0.001$ & 0.101 & $\begin{array}{l}0.080,0 \\
.123\end{array}$ & $<0.001$ \\
\hline MET & 0.021 & $\begin{array}{l}-0.0005 \\
0.043\end{array}$ & 0.055 & -0.0006 & $\begin{array}{l}-0.024 \\
0.022\end{array}$ & 0.958 \\
\hline $\begin{array}{l}\text { Diabetes } \\
\text { No } \\
\text { Yes }\end{array}$ & $\begin{array}{l}\text { Ref } \\
0.696\end{array}$ & $-0.028,1.42$ & 0.060 & 0.053 & $\begin{array}{l}-0.685 \\
0.792\end{array}$ & 0.887 \\
\hline $\begin{array}{l}\text { Hypertension } \\
\text { No } \\
\text { Yes }\end{array}$ & $\begin{array}{l}\text { Ref } \\
1.762\end{array}$ & $1.165,2.358$ & $<0.001$ & 0.998 & $0.334,1.66$ & 0.003 \\
\hline $\begin{array}{l}\text { Cardiac ischemic } \\
\text { disease } \\
\text { No } \\
\text { Yes }\end{array}$ & $\begin{array}{l}\text { Ref } \\
2.994\end{array}$ & $2.23,3.75$ & $<0.001$ & 2.21 & $1.42,3.007$ & 0.429 \\
\hline $\begin{array}{l}\text { Total amount of sleep in } \\
24 \text { hours }\end{array}$ & -0.084 & $-0.212,0.044$ & 0.198 & 0.025 & $\begin{array}{l}-0.103 \\
0.155\end{array}$ & 0.693 \\
\hline
\end{tabular}

BMI, body mass index; MET, metabolic equivalent of task 


\begin{tabular}{|c|c|c|c|c|c|c|}
\hline \multirow[t]{2}{*}{ Variables } & \multicolumn{3}{|l|}{ crude } & \multicolumn{3}{|c|}{ adjasted } \\
\hline & $\bar{B}$ & $95 \% \mathrm{~B}$ & P-value & $\mathrm{B}$ & $95 \% \mathrm{~B}$ & P-value \\
\hline$\overline{\text { Age }}$ & $\begin{array}{l}0 \\
.412\end{array}$ & $0.328,0.497$ & $<0.001$ & 0.331 & $0.225,0.437$ & $<0.001$ \\
\hline $\begin{array}{l}\text { Gender } \\
\text { Male } \\
\text { Female }\end{array}$ & $\begin{array}{l}\text { Ref } \\
19.38\end{array}$ & $17.84,20.93$ & $<0.001$ & 16.82 & $15.03,18.62$ & $<0.001$ \\
\hline $\begin{array}{l}\text { Marital status } \\
\text { Unmarried } \\
\text { Married } \\
\text { Widowed or divorced }\end{array}$ & $\begin{array}{l}\text { Ref } \\
-3.25 \\
6.24\end{array}$ & $\begin{array}{l}-7.52,1.009 \\
1.21,11.26\end{array}$ & $\begin{array}{r}0.135 \\
0.015\end{array}$ & $\begin{array}{l}-1.82 \\
-3.98\end{array}$ & $\begin{array}{l}-5.97,2.31 \\
-8.92,0.967\end{array}$ & $\begin{array}{l}0.387 \\
0.115\end{array}$ \\
\hline BMI & 0.899 & $0.738,1.061$ & $<0.001$ & 0.316 & $0.150,0.482$ & $<0.001$ \\
\hline Education level & -1.17 & $-1.37,-0.963$ & $<0.001$ & -0.093 & $-0.345,0.159$ & 0.470 \\
\hline Wrist circumference & -1.35 & $-1.94,-0.760$ & $<0.001$ & 1.32 & $0.712,1.940$ & $<0.001$ \\
\hline Hip circumference & 0.369 & $0.279,0.460$ & $<0.001$ & 0.152 & $0.061,0.243$ & 0.001 \\
\hline Waist circumference & 0.455 & $0.388,0.521$ & $<0.001$ & 0.168 & $0.099,0.238$ & $<0.001$ \\
\hline MET & -0.490 & $-0.563,-0.418$ & $<0.001$ & -0.234 & $-0.308,-0.159$ & $<0.001$ \\
\hline $\begin{array}{l}\text { Diabetes } \\
\text { No } \\
\text { Yes }\end{array}$ & $\begin{array}{l}\text { Ref } \\
7.40\end{array}$ & $5.01,9.80$ & $<0.001$ & 0.251 & $-2.14,2.64$ & 0.837 \\
\hline $\begin{array}{l}\text { Hypertension } \\
\text { No } \\
\text { Yes }\end{array}$ & $\begin{array}{l}\text { Ref } \\
10.97\end{array}$ & $9.01,12.93$ & $<0.001$ & 2.423 & $0.280,4.56$ & 0.027 \\
\hline $\begin{array}{l}\text { Cardiac ischemic } \\
\text { disease } \\
\text { No } \\
\text { Yes }\end{array}$ & $\begin{array}{l}\text { Ref } \\
8.08\end{array}$ & $5.56,10.59$ & $<0.001$ & 1.961 & $-0.587,4.51$ & 0.131 \\
\hline $\begin{array}{l}\text { Total amount of sleep } \\
\text { in } 24 \text { hours }\end{array}$ & -0.012 & $-0.437,0.412$ & 0.955 & - & - & - \\
\hline
\end{tabular}

BMI, body mass index; MET, metabolic equivalent of task 


\begin{tabular}{|c|c|c|c|c|c|c|}
\hline \multicolumn{7}{|c|}{$\begin{array}{l}\text { Table 5. Linear regression analysis of the association between QRS axis }{ }^{0} \text { and independent } \\
\text { variables }\end{array}$} \\
\hline \multirow[t]{2}{*}{ Variables } & \multicolumn{3}{|l|}{ Crude } & \multicolumn{3}{|c|}{ Adjusted } \\
\hline & $\mathrm{B}$ & $95 \%$ B & P-value & $\mathrm{B}$ & $95 \%$ B & P-value \\
\hline Age & -0.560 & $-0.651,-0.468$ & $<0.001$ & -0.454 & $-0.572,-0.336$ & $<0.001$ \\
\hline $\begin{array}{l}\text { Gender } \\
\text { Male } \\
\text { Female }\end{array}$ & $\begin{array}{l}\text { Ref } \\
-6.15\end{array}$ & $-7.89,-4.40$ & $<0.001$ & -8.43 & $-10.55,-6.31$ & $<0.001$ \\
\hline $\begin{array}{l}\text { Marital status } \\
\text { Unmarried } \\
\text { Married } \\
\text { Widowed or divorced }\end{array}$ & $\begin{array}{l}\text { Ref } \\
-3.10 \\
-6.96\end{array}$ & $\begin{array}{c}-7.75,1.55 \\
-12.44,-1.48\end{array}$ & $\begin{array}{l}0.191 \\
0.013\end{array}$ & $\begin{array}{c}2.618 \\
5.00\end{array}$ & $\begin{array}{l}-2.00,7.23 \\
-0.50,10.51\end{array}$ & $\begin{array}{l}0.267 \\
0.075\end{array}$ \\
\hline $\mathrm{BMI}$ & -1.51 & $-1.68,-1.34$ & $<0.001$ & -1.42 & $-1.61,-1.24$ & $<0.001$ \\
\hline Education level & 0.876 & $0.649,1.10$ & $<0.001$ & 0.003 & $-0.277,0.285$ & 0.979 \\
\hline Wrist circumference & -2.27 & $-2.91,-1.62$ & $<0.001$ & -3.45 & $-4.14,-2.76$ & $<0.001$ \\
\hline Hip circumference & -0.601 & $-0.699,-0.503$ & $<0.001$ & -0.598 & $-0.700,-0.496$ & $<0.001$ \\
\hline Waist circumference & -0.637 & $\begin{array}{l}-0.709 \\
-0.565\end{array}$ & $<0.001$ & -0.553 & $-0.630,-0.475$ & $<0.001$ \\
\hline MET & 0.223 & $0.143,0.303$ & $<0.001$ & 0.096 & $0.013,0.179$ & 0.023 \\
\hline $\begin{array}{l}\text { Diabetes } \\
\text { No } \\
\text { Yes }\end{array}$ & $\begin{array}{l}\text { Ref } \\
-7.27\end{array}$ & $-9.87,-4.66$ & $<0.001$ & -0.058 & $-2.72,2.60$ & 0.966 \\
\hline $\begin{array}{l}\text { Hypertension } \\
\text { No } \\
\text { Yes }\end{array}$ & $\begin{array}{l}\text { Ref } \\
-11.83\end{array}$ & $-13.96,-9.69$ & $<0.001$ & -3.84 & $-6.23,-1.45$ & 0.002 \\
\hline $\begin{array}{l}\text { Cardiac ischemic } \\
\text { disease } \\
\text { No } \\
\text { Yes }\end{array}$ & $\begin{array}{l}\text { Ref } \\
-8.45\end{array}$ & $-11.18,-5.72$ & $<0.001$ & -1.49 & $-4.33,1.33$ & 0.301 \\
\hline $\begin{array}{l}\text { Total amount of sleep } \\
\text { in } 24 \text { hours }\end{array}$ & 0.090 & $-0.372,0.552$ & 0.702 & - & & \\
\hline
\end{tabular}

BMI, body mass index; MET, metabolic equivalent of task 


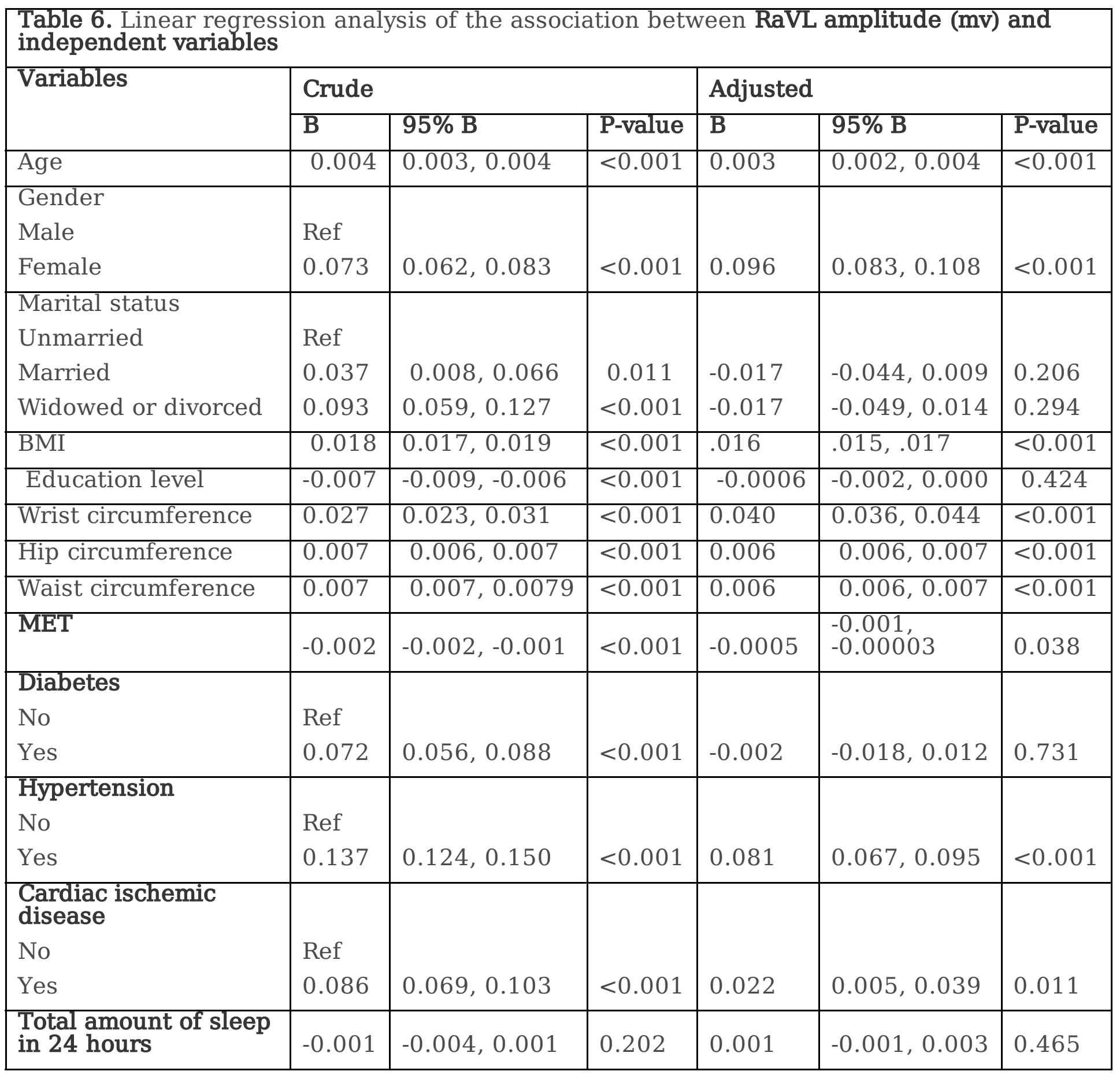

BMI, body mass index; MET, metabolic equivalent of task 


\begin{tabular}{|c|c|c|c|c|c|c|}
\hline \multirow[t]{2}{*}{ Variables } & \multicolumn{3}{|l|}{ Crude } & \multicolumn{3}{|c|}{ Adjusted } \\
\hline & $\bar{B}$ & $95 \% \mathrm{~B}$ & P-value & $\bar{B}$ & $95 \% \mathrm{~B}$ & P-value \\
\hline Age & -0.002 & $-0.003,-0.002$ & $<0.001$ & -0.002 & $-0.002,-0.001$ & $<0.001$ \\
\hline $\begin{array}{l}\text { Gender } \\
\text { Male } \\
\text { Female }\end{array}$ & $\begin{array}{l}\text { Ref } \\
0.003\end{array}$ & $-0.006,0.012$ & 0.505 & - & - & - \\
\hline $\begin{array}{l}\text { Marital status } \\
\text { Unmarried } \\
\text { Married } \\
\text { Widowed or } \\
\text { divorced }\end{array}$ & $\begin{array}{l}\text { Ref } \\
-0.018 \\
-0.022\end{array}$ & $\begin{array}{c}-0.043,0.006 \\
-0.052,0.007\end{array}$ & $\begin{array}{c}0.147 \\
0.137\end{array}$ & $\begin{array}{l}0.005 \\
0.025\end{array}$ & $\begin{array}{l}-0.019,0.030 \\
-0.004,0.055\end{array}$ & $\begin{array}{l}0.666 \\
0.100\end{array}$ \\
\hline$\overline{\mathrm{BMI}}$ & -0.003 & $-0.004,-0.002$ & $<0.001$ & -0.003 & $-0.004,-0.002$ & $<0.001$ \\
\hline Education level & 0.003 & $0.002,0.004$ & $<0.001$ & -0.0001 & $-0.001,0.001$ & 0.876 \\
\hline $\begin{array}{l}\text { Wrist } \\
\text { circumference }\end{array}$ & -0.008 & $-0.012,-0.005$ & $<0.001$ & -0.008 & $-0.012,-0.005$ & $<0.001$ \\
\hline Hip circumference & -0.001 & $-0.001,-0.0005$ & $<0.001$ & -0.001 & $-0.001,-0.0006$ & $<0.001$ \\
\hline $\begin{array}{l}\text { Waist } \\
\text { circumference }\end{array}$ & -0.001 & $-0.001,-0.001$ & $<0.001$ & -0.001 & $-0.001,-0.0007$ & $<0.001$ \\
\hline MET & 0.0002 & $\begin{array}{l}-0.0002 \\
0.0006\end{array}$ & 0.307 & - & - & - \\
\hline $\begin{array}{l}\text { Diabetes } \\
\text { No } \\
\text { Yes }\end{array}$ & $\begin{array}{l}\text { Ref } \\
-0.019\end{array}$ & $-0.033,-0.005$ & 0.006 & 0.008 & $-0.006,0.023$ & 0.255 \\
\hline $\begin{array}{l}\text { Hypertension } \\
\text { No } \\
\text { Yes }\end{array}$ & $\begin{array}{l}\text { Ref } \\
-0.054\end{array}$ & $-0.066,-0.043$ & $<0.001$ & -0.030 & $-0.043,-0.017$ & $<0.001$ \\
\hline $\begin{array}{l}\text { Cardiac ischemic } \\
\text { disease } \\
\text { No } \\
\text { Yes }\end{array}$ & $\begin{array}{l}\text { Ref } \\
-0.040\end{array}$ & $-0.054,-0.025$ & $<0.001$ & -0.010 & $-0.025,0.005$ & 0.189 \\
\hline $\begin{array}{l}\text { Total amount of } \\
\text { sleep in } 24 \text { hours }\end{array}$ & 0.002 & $-0.0003,0.004$ & 0.090 & 0.0002 & $-0.002,0.002$ & 0.854 \\
\hline
\end{tabular}

BMI, body mass index; MET, metabolic equivalent of task 